\title{
Pengaruh Kepemimpinan dan Disiplin Kerja Terhadap Kinerja Karyawan Pada Bagian Operasional PT. Bank Central Asia, TBK. Kantor Pusat Jakarta Barat
}

\author{
${ }^{1}$ Arief Budi Santoso, ${ }^{2}$ Fitriyanti \\ Dosen Fakultas Ekonomi Universitas Pamulang \\ Email:1.
}

\begin{abstract}
ABSTRAK
Penelitian ini bertujuan untuk mengetahui pengaruh kepemimpinan dan disiplin kerja terhadap kinerja karyawan pada bagian operasional PT. Bank Central Asia,Tbk kantor pusat Jakarta Barat.

Penilitian yang dilakukan bersifat deskriptif, metode pengumpulan data diantaranya dilakukan melalui studi kepustakaan serta studi lapangan dengan cara observasi, dan pembagian kuesioner atau angket. Adapun sampel dalam penelitian ini sebanyak 60 responden atau karyawan PT.Bank Central Asia,Tbk. Metode pembuatan skala untuk kuesioner atau angket menggunakan skala likert. Penelitian ini menggunakan metode kuantitatif. Kelayakan data pada penelitian ini diuji menggunakan Uji Validitas, Reliabilitas, Asumsi Klasik, Analisis Regresi Linear Berganda, melalui Koefisien Korelasi dan Koefisien Determinasi, pengujian Hipotesis melalui Uji t dan Uji F.

Hasil penelitian ini menunjukkan dua variabel independen yang diuji berpengaruh secara positif dan signifikan terhadap satu variabel dependen dengan persamaan regresi $\mathrm{Y}=10,759+0,275 \mathrm{X} 1+0,386 \mathrm{X} 2$. Dari pengujian Hipotesis menggunakan uji statistik Fhitung > Ftabel $(33,189>2,770)$ sehingga H0 ditolak dan $\mathrm{H} 1$ diterima. Artinya penelitian yang telah dilakukan menunjukkan hasil bahwa Kepemimpinan dan Disiplin Kerja terdapat pengaruh positif dan signifikan secara parsial dan simultan terhadap Kinerja Karyawan pada karyawan PT. Bank Central Asia,Tbk.
\end{abstract}

Kata Kunci : Kepemimpinan, Disiplin Kerja, Kinerja Karyawan. 


\section{PENDAHULUAN}

Dalam Kepemimpinan dan Disiplin Kerja sangat penting bagi karyawan PT. Bank Central Asia,Tbk terhadap kinerja kerja, dalam penelitian ini untuk mengukur Kepemimpinan dan Disiplin Kerja karyawan menggunakan hasil pra riset kepemimpinan dan jumlah absensi karyawan.

kepemimpinan kerja pada karyawan PT Bank BCA hasil pra riset ke 10 orang karyawan dari 60 orang karyawan menunjukan hasil nilai rata- rata skor adalah 3,23. Kepemimpinan kerja pada karyawan masih kurang baik kepemimpinannya. Dapat di lihat di atas bahwa pimpinan belum mampu memberitahukan dengan jelas apa yang harus dikerjakan kepada karyawannya, kemudian pimpinan masih kurang bersikap adil dalam memberikan tugas dan sanksi kepada karyawannya serta kurang adanya kerja sama antar pemimpin dan karyawan dengan berkomunikasi dua arah kepada pegawai dalam memecahkan masalah.

Tabel 1.

Absensi Karyawan PT.BCA Per Juni 2018 - Mei 2019

Sumber :HRD PT Bank Central Asia Tbk tahun 2018 - 2019.

Tabel diatas dapat dijelaskan bahwa ketidakhadiran pada PT. Bank Central Asia,Tbk sangat tinggi.

Berdasarkan latar belakang masalah tersebut, peneliti merasa tertarik untuk mengadakan penelitian tentang "Pengaruh Kepemimpinan Dan Disiplin Kerja Terhadap Kinerja Karyawan Karyawan Pada Pt. Bank Central Asia,Tbk."

\section{RUMUSAN MASALAH}

1. Adakah pengaruh kepemimpinan terhadap kinerja karyawan pada PT. Bank Central Asia Tbk ?

2. Adakah pengaruh Disiplin kerja terhadap kinerja karyawan pada PT. Bank Central Asia Tbk?

3. Adakah pengaruh antara kepemimpinan dan Disiplin kerja terhadap kinerja karyawan secara simultan pada PT. Bank Central Asia Tbk?

\section{KAJIAN TEORI \\ Kepemimpinan}

Menurut Terry dalam Edy Sutrisno (2017:214) menganggap kepemimpinan sebagai kegiatan untuk mempengaruhi orang agar bekerja dengan rela untuk mencapai tujuan bersama.

\section{Disiplin Kerja}

Menurut Hasibuan (2018:193) kedisiplinan adalah fungsi operatif keenam dari manajemen sumber daya manusia. Kedisiplinan merupakan fungsi operatif MSDM yang terpenting karena semakin baik disiplin karyawan, semakin tinggi prestasi kerja yang dapat dicapainya, tanpa disiplin karyawan yang baik, sulit bagi organisasi perusahaan mencapai hasil yang optimal.

\section{METODE PENELITIAN}

\section{Populasi}

Populasi Menurut Sugiyono (2017:215) "Populasi adalah jumlah wilayah generalisasi yang terdiri atas obyek dan karakteristik yang ditetapkan oleh peneliti dan kemudian ditarik kesimpulannya".

Dalam penelitian ini yang dijadikan populasi adalah pegawai yang berjumlah 60 orang karyawan. 
2. Sampel

Teknik sampel yang digunakan dalam penelitian ini adalah sampling jenuh yaitu teknik penentuan sampel bila semua anggota populasi digunakan sebagai sampel. (Sugiyono 2017:82)

Adapun sempling jenuh yang digunakan adalah seluruh karyawan PT.Bank Central Asia,Tbk yang berjumlah 60 karyawan.

3. Jenis Penelitian

Penelitian ini bersifat asosiatif yaitu dapat dibangun suatu teori yang berfungsi untuk menjelaskan, meramalkan dan mengontrol suatu gejala. (Sugiyono 2017:44) .

4. Metode Analisis Data

Dalam menganalisis data digunakan uji instrumen, uji asumsi klasik, Auto korelasi, regresi berganda , koefisien korelasi dan uji hipotesis

\section{HASIL PENELITIAN DAN PEMBAHASAN}

\section{Uji Auto korelasi}

Untuk mengetahui ada tidaknya autokorelasi Uji Darbin-Watson (DW test) berikut ini kriteria yang menjadi acuannya:

Tabel 1 Pedoman Interpretasi Uji Durbin-Watson

\begin{tabular}{|l|c|}
\hline Kriteria & Keterangan \\
\hline$<1,000$ & Ada autokorelasi \\
\hline $1,100-$ & Tanpa kesimpulan \\
$1,560-$ & \\
\hline $1,550-$ & Tidak ada autokorelasi \\
$2,460-$ & \\
\hline $2,460-$ & Tanpa kesimpulan \\
2,900 & \\
\hline$>2,900$ & Ada autokorelasi \\
\hline
\end{tabular}

Sumber : Sugiyono (2016:184)

Sumber: Data Primer, tahun 2019, diolah dengan SPSS Versi 25
Tabel 2

Hasil Pengujian Uji Auto Korelasi

Model Summary ${ }^{b}$

\begin{tabular}{|c|c|c|c|c|c|}
\hline $\begin{array}{l}\text { Mode } \\
\text { | }\end{array}$ & $\mathrm{R}$ & $\begin{array}{c}\text { R } \\
\text { Squa } \\
\text { re }\end{array}$ & $\begin{array}{l}\text { Adjusted } \\
\text { R Square }\end{array}$ & $\begin{array}{l}\text { Std. } \\
\text { Error of } \\
\text { the } \\
\text { Estimate }\end{array}$ & $\begin{array}{l}\text { Durbin- } \\
\text { Watson }\end{array}$ \\
\hline & $.733^{a}$ & .538 & .522 & 2.964 & 2.052 \\
\hline
\end{tabular}

a. Predictors: (Constant), Disiplin Kerja(X1), Kepemimpinan )X1)

b. Dependent Variable: Kinerja Karyawan $(\mathrm{Y})$

Dari tabel diatas, diperoleh nilai

Durbin-Watson sebesar 2.052 yang berada diantara interval $1.550-2.460$ sesuai dengan ketentuan maka model regresi ini tidak ada autokorelasi.

\section{Analisis Regresi Linier Berganda}

Berikut ini hasil olahan data regresi dengan SPSS versi 25 yang dapat dilihat pada tabel berikut ini:

Tabel 3

Hasil Pengujian Regresi Berganda

Variabel Kepemimpinan $\left(\mathrm{X}_{1}\right)$ dan

Disiplin Kerja $\left(\mathrm{X}_{3}\right)$ Terhadap Kinerja

\section{Coefficientsa}

$$
\text { Karyawan (Y) }
$$

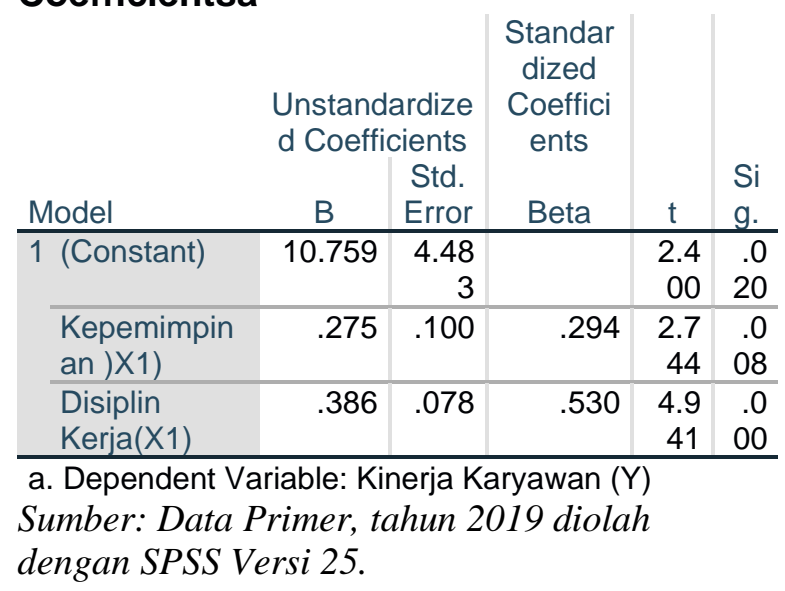

Adapun persamaan regresi linear berganda dapat dilihat pada tabel diatas dengan persamaan sebagai 
berikut: $Y=10,759+0,275 \mathrm{X}_{1}+$ $0,386 \mathrm{X}_{2}$

Dimana : Nilai konstanta sebesar 10,759 diartikan bahwa jika variabel Kepemimpinan $\left(\mathrm{X}_{1}\right)$ dan disiplin kerja $\left(\mathrm{X}_{2}\right)$ tidak ada maka telah terdapat nilai Kinerja karyawan (Y) sebesar 10,759 point.

1) Nilai Kepemimpinan (X1) 0,275 diartikan apabila konstanta tetap dan tidak ada perubahan pada variabel disiplin kerja (X2), maka setiap perubahan 1 unit pada variabel Kepemimpinan (X1) akan mengakibatkan terjadinya perubahan pada Kinerja karyawan (Y) sebesar 0,275 point.

2) Nilai disiplin kerja (X2) 0,386 diartikan apabila konstanta tetap dan tidak ada perubahan pada variabel Kepemimpinan (X1), maka setiap perubahan 1 unit pada variabel disiplin kerja (X2) akan mengakibatkan terjadinya perubahan pada Kinerja karyawan (Y) sebesar 0,386 point

Tabel 4

Analisis Koefisien Korelasi Secara Simultan Antara Kepemimpinan $\left(\mathrm{X}_{1}\right)$ dan Disiplin Kerja $\left(\mathrm{X}_{2}\right)$ Terhadap

Kinerja Karyawan (Y)

\begin{tabular}{|c|c|c|c|c|}
\hline \multicolumn{5}{|c|}{ Model Summary } \\
\hline $\begin{array}{l}\text { Mo } \\
\text { del }\end{array}$ & $\mathrm{R}$ & $\begin{array}{c}\mathrm{R} \\
\text { Squ } \\
\text { are }\end{array}$ & $\begin{array}{l}\text { Adjust } \\
\text { ed R } \\
\text { Square }\end{array}$ & $\begin{array}{l}\text { Std. Error of } \\
\text { the Estimate }\end{array}$ \\
\hline 1 & $\begin{array}{r}.73 \\
3^{\mathrm{a}}\end{array}$ & $\begin{array}{r}.53 \\
8\end{array}$ & .522 & 2.964 \\
\hline
\end{tabular}

\section{Hasil}

SSumber: Data Primer tahun 2019, diolah dengan SPSS Versi 25

Berdasarkan pada hasil pengujian pada tabel di atas, diperoleh nilai $R$ (koefisien korelasi) sebesar 0,733 artinya variabel Kepemimpinan $\left(\mathrm{X}_{1}\right)$ dan disiplin kerja (X2) mempunyai tingkat hubungan yang kuat terhadap Kinerja karyawan (Y).

\section{Analisis Koefisien Determinasi}

(Kd) dipergunakan untuk mengetahui seberapa besar tingkat hubungan atau pengaruh antara variabel Disiplin Kerja dan Motivasi Kerja terhadap variabel Kinerja Karyawan.

Hasil Analisis Koefisien Determinasi Secara Simultan Antara Variabel Kepemimpinan $\left(\mathrm{X}_{1}\right)$ dan Disiplin Kerja (X2) Terhadap Kinerja Karyawan (Y)

\begin{tabular}{|c|c|c|c|c|}
\hline & & Mod & $\begin{array}{l}\text { abel } 6 \\
\text { Sumr }\end{array}$ & ary \\
\hline $\begin{array}{l}\text { Mo } \\
\text { del }\end{array}$ & $\mathrm{R}$ & $\begin{array}{l}\mathrm{R} \\
\text { Squ } \\
\text { are }\end{array}$ & $\begin{array}{c}\text { Adjust } \\
\text { ed R } \\
\text { Square }\end{array}$ & $\begin{array}{l}\text { Std. Error of } \\
\text { the Estimate }\end{array}$ \\
\hline 1 & $\begin{array}{r}.73 \\
3^{a}\end{array}$ & .538 & .522 & 2.964 \\
\hline
\end{tabular}

a. Predictors: (Constant), Disiplin Kerja(X1), Kepemimpinan )X1)

Sumber: Data Primer tahun 2019, diolah dengan SPSS Versi 25

Berdasarkan pada hasil pengujian pada tabel di atas, diperoleh a. Dependent Variable: Kinerja Karyawan $(\mathrm{Y})$ nilai $R$-square sebesar 0,538 maka dapat disimpulkan bahwa variabel Kepemimpinan $\left(\mathrm{X}_{1}\right)$ dan disiplin kerja (X2) berpengaruh terhadap variabel Kinerja karyawan (Y) sebesar 53,8\% sedangkan sisanya sebesar 46,2\% dipengaruhi oleh faktor lain yang tidak dilakukan penelitian.

\section{Uji Hipotesis}

\section{Uji Parsial (t hitung)}

Pengujian hipotesis variabel Kepemimpinan $\left(\mathrm{X}_{1}\right)$ dan disiplin kerja 
(X2) terhadap Kinerja karyawan (Y) dilakukan dengan uji $\mathrm{t}$ (uji secara parsial). Dalam penelitian ini digunakan kriteria signifikansi 5\% $(0,05)$ dengan membandingkan $t$ hitung dengan $t_{\text {tabel }}$ yaitu sebagai berikut:

(a) Jika nilai $t_{\text {hitung }}<t_{\text {tabel }}$ : berarti $\mathrm{H}_{0}$ diterima dan $\mathrm{H}_{1}$ ditolak

(b) Jika nilai $t_{\text {hitung }}>t_{\text {tabel }}$ :berarti $\mathrm{H}_{0}$ ditolak dan $\mathrm{H}_{1}$ diterima

Adapun untuk menentukan besarnya $\mathrm{t}$ tabel dicari dengan menggunakan rumus berikut ini: $t_{\text {tabel }}=$ t $\alpha . \mathrm{df}$ (Taraf Alpha $x$ Degree of Freedom) $\alpha=$ tarif nyata $5 \%$ $\mathrm{df}=(\mathrm{n}-2)$, maka diperoleh $(60-2)=58$, maka $t_{\text {tabel }}=2,002$

Kriteria dikatakan signifikan jika nilai $t_{\text {hitung }}>t_{\text {tabel }}$ atau $\rho$ value $<$ Sig.0,05

Pengaruh Disiplin Kerja ( $\left.\mathbf{X}_{1}\right)$ Terhadap Kinerja Karyawan Karyawan (Y)

Menentukan

rumusan

hipotesisnya adalah :

Adapun hasil pengolahan data menggunakan program SPSS Versi 25, dengan hasil sebagai berikut :

Tabel 7 Hasil Uji Hipotesis (Uji t)

Variabel Kepemimpinan $\left(\mathrm{X}_{1}\right)$

Terhadap Kinerja Karyawan (Y)

\begin{tabular}{|c|c|c|c|c|c|}
\hline \multicolumn{6}{|c|}{ Coefficients $^{a}$} \\
\hline & $\begin{array}{r}\text { Uns } \\
\text { d } \\
\text { Coe }\end{array}$ & $\begin{array}{l}\text { andar } \\
\text { zed } \\
\text { ficient } \\
\text { s }\end{array}$ & $\begin{array}{c}\text { Standa } \\
\text { rdized } \\
\text { Coeffici } \\
\text { ents }\end{array}$ & & \\
\hline Model & $\mathrm{B}$ & $\begin{array}{l}\text { Std. } \\
\text { Error }\end{array}$ & Beta & $t$ & $\begin{array}{l}\mathrm{Si} \\
\mathrm{g} .\end{array}$ \\
\hline 1 (Constant) & $\begin{array}{r}22 . \\
30 \\
5\end{array}$ & $\begin{array}{r}4.53 \\
3\end{array}$ & & $\begin{array}{r}4.92 \\
1\end{array}$ & $\begin{array}{r}.0 \\
0 \\
0\end{array}$ \\
\hline $\begin{array}{l}\text { Kepemimpin } \\
\text { an )X1) }\end{array}$ & $\begin{array}{r}.54 \\
5\end{array}$ & .100 & .583 & $\begin{array}{r}5.46 \\
8\end{array}$ & $\begin{array}{l}.0 \\
0 \\
0\end{array}$ \\
\hline
\end{tabular}

a. Dependent Variable: Kinerja Karyawan (Y)

Sumber : Data Primer tahun 2019,

diolah dengan SPSS Versi 25.
Berdasarkan pada hasil pengujian pada tabel di atas diperoleh nilai $t$ hitung $>t$ tabel atau $(5,468>2,002)$ Hal tersebut juga diperkuat dengan nilai $\rho$ value < Sig. 0,05 atau $(0,000$ $<0,05)$. Dengan demikian maka $\mathrm{H}_{0}$ ditolak dan $\mathrm{H}_{1}$ diterima, hal ini menunjukkan bahwa terdapat pengaruh yang signifikan secara parsial antara Kepemimpinan terhadap Kinerja karyawan pada PT.Bank Central Asia, Tbk.

\section{A. Pengaruh Motivasi Kerja ( $\left.\mathbf{X}_{2}\right)$ Terhadap Kinerja Karyawan Karyawan (Y)}

Adapun hasil pengolahan dengan hasil sebagai berikut :

\section{Tabel 8}

Hasil Uji t Variabel Disiplin Kerja

$\left(X_{2}\right)$ Terhadap Kinerja Karyawan

(Y)

\section{Coefficients $^{\mathrm{a}}$}

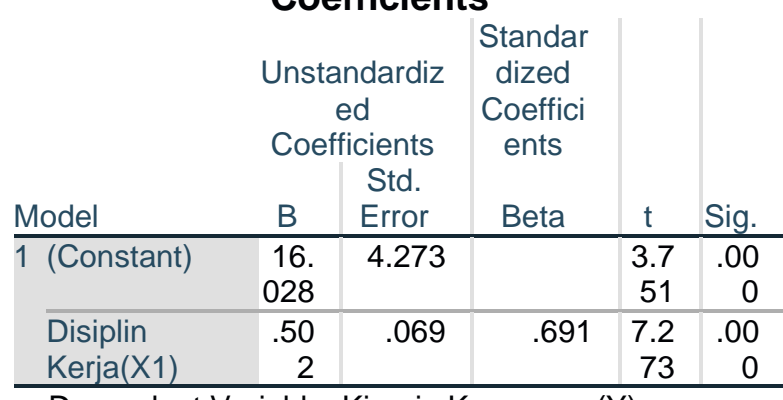

a. Dependent Variable: Kinerja Karyawan (Y)

Sumber : Data Primer tahun 2019, diolah dengan SPSS Versi 25.

Dari tabel diatas diperoleh nilai $t$ hitung $>t$ tabel atau $(7,273>$ 2,002). Hal tersebut juga diperkuat dengan nilai $\rho$ value $<$ Sig.0,05 atau $(0,000<0,05)$. Dengan demikian maka $\mathrm{H}_{0}$ ditolak dan $\mathrm{H}_{2}$ diterima, hal ini menunjukkan bahwa terdapat pengaruh yang yang signifikan secara parsial antara disiplin kerja terhadap Kinerja karyawan pada PT.Bank Central Asia, Tbk. 
B. Uji F (Simultan)

Tabel 9 Hasil Hipotesis (Uji F)

Secara Simultan Antara

Kepemimpinan (X1) dan Disiplin

Kerja (X2) Terhadap Kinerja Karyawan (Y)

\begin{tabular}{lc|r|r|r|r}
\multicolumn{7}{c}{ ANOVA $^{\mathrm{a}}$} \\
Model & $\begin{array}{c}\text { Sum of } \\
\text { Squares }\end{array}$ & df & $\begin{array}{c}\text { Mean } \\
\text { Square }\end{array}$ & \multicolumn{1}{c}{$\mathrm{F}$} & \multicolumn{1}{c}{ Sig } \\
\hline $\begin{array}{l}\text { Regre } \\
\text { ssion }\end{array}$ & 583.162 & 2 & 291.58 & 33.1 & .00 \\
\hline $\begin{array}{l}\text { Resid } \\
\text { ual }\end{array}$ & 500.771 & 57 & 8.785 & & $0^{\mathrm{b}}$ \\
\hline \multicolumn{1}{l}{ Total } & 1083.933 & 59 & & & \\
\hline
\end{tabular}

a. Dependent Variable: Kinerja Karyawan $(\mathrm{Y})$

b. Predictors: (Constant), Disiplin Kerja(X1), Kepemimpinan )X1)

Sumber : Data Primer tahun 2019, diolah dengan SPSS Versi 25.

Dari Tabel diatas, diperoleh nilai $F$ hitung $>\mathrm{F}_{\text {tabel }}$ atau $(33,189>2,770)$, hal ini juga diperkuat dengan $\rho$ value < Sig.0,05 atau $(0,000<0,05)$. Dengan demikian maka $\mathrm{H}_{0}$ ditolak dan $\mathrm{H}_{3}$ diterima, hal ini menunjukkan bahwa terdapat pengaruh yang signifikan secara simultan antara Kepemimpinan dan disiplin kerja terhadap Kinerja karyawan pada PT.Bank Central Asia, Tbk.

\section{PEMBAHASAN \\ PENELITIAN}

HASIL

1. Pengaruh Kepemimpinan terhadap Kinerja karyawan pada PT.Bank Central Asia, Tbk.berpengaruh signifikan dari pengujian hipotesis diperoleh $\mathrm{t}$ hitung > t tabel atau $(5,468>2,002)$, dengan demikian $\mathrm{H} 0$ ditolak dan H1 diterima artinya terdapat pengaruh signifikan antara Kepemimpinan terhadap Kinerja karyawan

2. Pengaruh Disiplin kerja terhadap Kinerja karyawan pada
PT.Bank Central Asia, Tbk berpengaruh signifikan dari pengujian hipotesis diperoleh $t$ hitung > $\mathrm{t}$ tabel atau $(7,273>$ 2,002), dengan demikian $\mathrm{H} 0$ ditolak dan $\mathrm{H} 2$ diterima artinya terdapat pengaruh signifikan antara disiplin kerja terhadap Kinerja karyawan (Y)

3. Pengaruh kepemimpinan dan disiplin kerja terhadap kinerja karyawan di PT. Bank Central Asia,Tbk. Berpengaruh secar simultan dengan persamaan regresi $\mathrm{Y}=10,759+0,275 \mathrm{X} 1+0,386 \mathrm{X} 2$. Dari pengujian hipotesis diperoleh nilai $\mathrm{F}$ hitung $>\mathrm{F}$ tabel atau $(33,189$ $>$ 2,770), dengan demikian $\mathrm{HO}$ ditolak dan H3 diterima. Artinya terdapat pengaruh signifikan secara simultan antara Kepemimpinan dan disiplin kerja terhadap Kinerja karyawan di PT.Bank Central Asia, Tbk

\section{KESIMPULAN DAN SARAN}

\section{A. Kesimpulan}

1. Kepemimpinan berpengaruh signifikan terhadap Kinerja karyawan pada PT.Bank Central Asia, Tbk. Dari pengujian hipotesis diperoleh $\mathrm{t}$ hitung $>\mathrm{t}$ tabel atau (5,468> 2,002), dengan demikian $\mathrm{H}_{0}$ ditolak dan $\mathrm{H}_{1}$ diterima artinya terdapat pengaruh signifikan antara Kepemimpinan terhadap Kinerja karyawan

2. Disiplin kerja berpengaruh signifikan terhadap Kinerja karyawan pada PT.Bank Central Asia, Tbk. Dari pengujian hipotesis diperoleh $\mathrm{t}$ hitung $>\mathrm{t}$ tabel atau $(7,273>2,002)$, dengan demikian $\mathrm{H}_{0}$ ditolak dan $\mathrm{H}_{2}$ diterima artinya terdapat 
pengaruh signifikan antara disiplin kerja terhadap Kinerja karyawan (Y)

3. Berdasarkan hasil penelitian, menunjukkan bahwa kepemimpinan dan disiplin kerja berpengaruh signifikan terhadap kinerja karyawan di PT. Bank Central Asia,Tbk. Dengan persamaan regresi $\mathrm{Y}=10,759+$ $0,275 X_{1}+0,386 X_{2}$. Dari pengujian hipotesis diperoleh nilai $F_{\text {hitung }}>F_{\text {tabel }}$ atau $(33,189$ $>2,770$ ), dengan demikian $\mathrm{H}_{0}$ ditolak dan $\mathrm{H}_{3}$ diterima. Artinya terdapat pengaruh signifikan secara simultan antara Kepemimpinan dan disiplin kerja terhadap Kinerja karyawan di PT.Bank Central Asia, Tbk

\section{B. Saran}

1. PT.Bank Central Asia, Tbk, perlu lebih baik lagi pimpinan harus konsisten dalam menerima masukan dari karyawan sehingga karyawan merasa di hargai dan di beri kesempatan untuk bisa mengasah kemampuanya.

2. PT.Bank Central Asia, Tbk, perlu lebih baik lagi pimpinan harus secara konsisten hadir di tempat kerja agar dapat mengawasi dan memberikan petunjuk jika bawahan mengalami kesulitan sehingga pekerjaan dapat di selesaikan tepat waktu.

3. PT.Bank Central Asia, Tbk, harus lebih baik lagi pimpinan harus konsisten dalam menjalin kerja sama antara atasan dan bawahan dengan baik sehingga karyawan nyaman dalam bekerja dan mendapatkan hasil kinerja yang optimal.

\section{DAFTAR PUSTAKA}

A.A Anwar Prabu Mangkunegara, "Manajemen Sumber Daya Manusia Perusahaan", Cetakan Ke Empat Belas, Remaja Rosdakarya, Bandung, 2017.

A.A Anwar Prabu Mangkunegara, Keith Davis, "Manajemen Sumber Daya Manusia Perusahaan", Cetakan Ke Empat Belas, Remaja Rosdakarya, Bandung, 2017.

Afandi, Pandi, "Manajemen Concept dan Indicator Human Resources Management.", Edisi Pertama, Cetakan Pertama, Budi Utama, Yogyakarta, 2016

Bangun Wilson, "Manajemen Sumber Daya Manusia", Erlangga, Jakarta, 2012.

Effendy, "Ilmu, Komunikasi Teori dan Praktek Komunikasi.", Citra Aditia Bakti, Bandung, 2015

Ghozali "Aplikasi Analisis

Multivariate dengan Program SPSS", Edisi Kelima, Badan Penerbit Undip, Semarang, 2017

Halsey, George d, "Bagaimana Memimpin dan Mengawasi Pegawai Anda". Edisi Terjemahan, Rineka Cipta, Jakarta, 2012.

Handayani, R. D. "Pengaruh Semangat Kerja Dan Disiplin Kerja Terhadap Kinerja PNSBalista Lembang", Journal Of Pariwisata, II, I. 2016.

Hasibuan, Malayu S P, "Manajemen Sumber Daya Manusia”. Cetakan Kesembilan Belas Bumi Aksara, Jakarta Timur, 2016. 
Hasibuan, Malayu S P, "Manajemen Sumber Daya Manusia". Cetakan Kedua Puluh dua Bumi Aksara, Jakarta Timur, 2018

Hasibuan, Malayu S P, "Manajemen Sumber Daya Manusia”. Cetakan Ketujuh belas Bumi Aksara, Jakarta Timur, 2013

Paramitadewi, F, Suharsimi, "Pengaruh Beban Kerja Dan Kompensasi Terhadap Kinerja Pegawai Sekretariat Pemerintah Daerah Kabupaten Tabanan", E-Jurnal Manajemen Unud, , 6(6).2017

Respatiningsih I. \& Sudirjo, "Pengaruh Komitmen Organisasi, Motivasi, Kapabilitas dan Kepuasan Kerja Terhadap Kinerja Pegawai", Serat, Acitya, (3), 56.

Rivai, Veitzal, "Manajemen Sumber Daya Manusia Untuk Perusahaan : Dari Teori Ke Praktik", Cetakan Ke Tujuh, Rajagrafindo Persada, Jakarta 2015

Sedarmayanti, "Manajemen Sumber Daya Manusia", Cetakan Ke Sembilan, Refika Aditama, Bandung, 2017.

Sigian, Sondang P, "Manajemen Sumber Daya Manusia", Cetakan Ke Sembilan, Rineka Cipta, Jakarta, 2015.

Sobarna, A., Hambali, S., Sutiswo, S., \& Sunarsi, D. (2020). The influence learning used $\mathrm{ABC}$ run exercise on the sprint capabilities. Jurnal Konseling dan Pendidikan, 8(2), 67-71.

Soekarso, Iskandar Putong, "Kepemimpinan Kajian Teoritis
Dan Praktis", Edisi Pertama, Erlangga, Jakarta, 2015

Sugiyono, "Metode Penelitian Kuantitatif, Kualitatif, dan $R \& D$.", Alfabeta, Bandung, 2018

Sugiyono, "Metode Penelitian", Cetakan Ke Dua Puluh Enam, Alfabeta, Bandung, 2018.

Sunarsi, D. (2018). Buku Ajar:

Seminar Perencanaan Sumber

Daya Manusia. Tangerang

Selatan: Asmoro Mediatama

Sunarsi, D. (2018). Pengembangan Sumber Daya Manusia Strategik \& Karakterisrik Sistem Pendukungnya : Sebuah Tinjauan. Jurnal Ilmiah MEA (Manajemen, Ekonomi, \& Akuntansi), 2(3), $178-194$.

Sunarsi, D. (2019). Seminar Sumber Daya Manusia. Tangerang Selatan: Unpam Press

Sutrisno, E, Singodimedjo ., "Manajemen Sumber Daya Manusia", Cetakan Ke Sembilan, Kencana, Jakarta, 2017.

Sutrisno, E., "Manajemen Sumber Daya Manusia", Prenada Media, Jakarta, 2015.

Sutrisno, Edy , "Teori Dan Praktek Kepemimpinan", Cetakan Ke Enam, Kencana, Jakarta, 2017.

Wibowo, "Kepemimpinan Kajian Teoritis Dan Praktis", Edisi Pertama, Raja Grafindo Persada, Depok, 2015

Wibowo, "Manajemen Kinerja", Edisi kelima, Cetakan ke duabelas, Raja Grafindo Persada, Depok, 2017 